\title{
Silicon as a Phase Change Material: Performance of h-BN Ceramic During Multi-Cycle Melting/Solidification of Silicon
}

\author{
WOJCIECH POLKOWSKI ${ }^{1,4}{ }^{1,4}$ NATALIA SOBCZAK, ${ }^{1,2,5}$ \\ ADELAJDA POLKOWSKA, ${ }^{1,6}$ GRZEGORZ BRUZDA, ${ }^{1,7}$ \\ ARTUR KUDYBA, ${ }^{1,8}$ and DONATELLA GIURANNO ${ }^{1,3,9}$
}

\begin{abstract}
1.-Foundry Research Institute, Zakopiańska 73 Str., 30-426 Krakow, Poland. 2.-Institute of Precision Mechanics, Duchnicka 3 Str, 01-796 Warsaw, Poland. 3.-CNR - Institute of Condensed Matter Chemistry and Technologies for Energy, Via E. De Marini, 6-16149 Genoa, Italy. 4.-email: wojciech.polkowski@iod.krakow.pl. 5.—e-mail: natalia.sobczak@iod.krakow.pl. 6.—e-mail: adelajda.polkowska@iod.krakow.pl. 7.—e-mail: grzegorz.bruzda@iod.krakow.pl. 8.—e-mail: artur.kudyba@iod.krakow.pl. 9.—e-mail: donatella.giuranno@ge.icmate.cnr.it
\end{abstract}

Silicon has recently been recognized as a potentially attractive phase change material for ultra-high-temperature latent heat thermal energy storage (LHTES) and conversion systems. It has been proposed that the utilization of silicon's latent heat should drastically increase the performance of LHTES devices in terms of operational temperatures and available energy density. Nevertheless, in order to ensure a high reliability and long lifetime of the system, proper ceramic materials that are able to withstand contact heating and cooling cycles during consecutive melting/solidification steps need to be examined and selected. Previously, we have documented that hexagonal boron nitride (h-BN) is the only ceramic that shows non-wettability and limited reactivity in contact with molten silicon at temperatures up to $1650^{\circ} \mathrm{C}$. In this work, we present for the first time the results of experimental research on the performance of a Si/h-BN system upon cycling melting/solidification processes. For this reason, the Si/h-BN couple was subjected to a sessile drop experiment containing 15 cycles of heating/cooling between $1300^{\circ} \mathrm{C}$ and $1450^{\circ} \mathrm{C}$. During the test, temperatures of specific events as well as contact angle values were recorded. After the test, the structure and surface morphology of the solidified $\mathrm{Si} / \mathrm{h}-\mathrm{BN}$ couple were characterized by means of scanning electron microscopy.

\section{INTRODUCTION}

Latent heat thermal energy storage (LHTES)based devices are utilized to produce electricity by converting heat absorbed/released during phase transformations of a material (a so-called phase change material; PCM) subjected to cyclic heating/cooling schemes. The current and perspective application fields of LHTES devices cover, for example, terrestrial or space solar energy systems. ${ }^{1-3}$ Very recently, it has been proposed that the introduction of silicon as the PCM should significantly overcome limitations of state-of-theart molten salt-based LHTES systems, both in terms of operational temperatures and available energy density. ${ }^{2}$ However, in order to move the Sibased LHTES system from a designer's desk to real industrial applications, the performance of ceramics intended to be used for building the PCM container has to be a priori experimentally evaluated. The basic assumption for the selection of proper ceramics is their "inertness" during long-term storage of solid/liquid state silicon. In other words, the selected ceramic material should exhibit a non-wetting behavior and a limited degradation (a lack of reactively formed interfacial products due to a direct reaction between $\mathrm{Si}$ and contacting refractory). However, from a literature review, ${ }^{4,5}$ almost all conventional ceramic materials, such as oxides, borides, carbides or nitrides, are well-wettable by molten silicon (i.e., they are characterized by contact angle $\theta$ values below $90^{\circ}$ ). The one reported exception in this field is hexagonal boron nitride (h$\mathrm{BN}$ ) that shows non-wettability at temperatures up 
to $1500^{\circ} \mathrm{C} .{ }^{5}$ In our previous work, ${ }^{6}$ we documented that this non-wetting behavior is maintained at temperatures up to $1650^{\circ} \mathrm{C}$, while the high-temperature interaction mechanism in the $\mathrm{Si} / \mathrm{h}-\mathrm{BN}$ system is dominated by a slight dissolution of the h-BN ceramic in molten $\mathrm{Si}$, followed by the reprecipitation of h-BN platelets during cooling. Furthermore, there were no continuous products reactively formed at the $\mathrm{Si} / \mathrm{h}-\mathrm{BN}$ interface. Since the observed high-temperature performance of the h-BN ceramic in contact with liquid $\mathrm{Si}$ allows for its preliminary selection as a good candidate for the PCM container, further examinations still need to be performed in order to assess its reliability upon consecutive melting/solidification steps.

Therefore, the main purpose of this work is to experimentally evaluate the wettability and reactivity in the $\mathrm{Si} / \mathrm{h}-\mathrm{BN}$ system subjected to hightemperature cycling phase changes.

\section{MATERIALS AND METHODS}

The materials investigated were ultra-high-purity silicon $(7 \mathrm{~N})$ and the commercially available hot-sintered h-BN ceramics (Henze HeBoSint D100, Germany). More details on the examined materials and applied sample preparation routes are described elsewhere. ${ }^{6}$ The $\mathrm{Si} / \mathrm{h}-\mathrm{BN}$ couple was subjected to sessile drop experiments performed by using an experimental complex for the investigation of high-temperature capillarity phenomena, described elsewhere. ${ }^{7}$
The applied testing procedure (schematically shown in Fig. 1) included 15 cycles composed of (1) heating to $1450^{\circ} \mathrm{C}$ at a rate of $15^{\circ} \mathrm{C} / \mathrm{min}$ and holding for $5 \mathrm{~min}$, and (2) cooling to $1300^{\circ} \mathrm{C}$ at a rate of $10^{\circ} \mathrm{C} /$ $\min$.

After 10 cycles, the Si/h-BN couple was cooled to room temperature, and then subjected to 5 more cycles of heating/cooling. Although a predicted real heating/cooling scheme in the Si-based LHTES device will involve much lower heating/cooling rates, the temperature profile used was applied to examine the materials' behavior under "forced" conditions which should accelerate their potential degradation. The test was started under ultra-high vacuum conditions ( $p=10^{-7}$ mbar), and then, during the first cycle, a static argon ( $p=850-900$ mbar $)$ was introduced at $800^{\circ} \mathrm{C}$ in order to suppress evaporation of the silicon. During the test, the images of the $\mathrm{Si} / \mathrm{h}-\mathrm{BN}$ couple were in situ recorded by a high-speed camera (at 100 frames per s), and then used to compile a video and calculate the contact angle values. Moreover, real-time visual observation of the couple was made during each heating/cooling cycle in order to determine the corresponding melting and solidification temperatures.

When the test was over, the solidified couple was removed from the chamber and subjected to a structural characterization by using an FEI Scios ${ }^{\mathrm{TM}}$ field emission gun scanning electron microscope

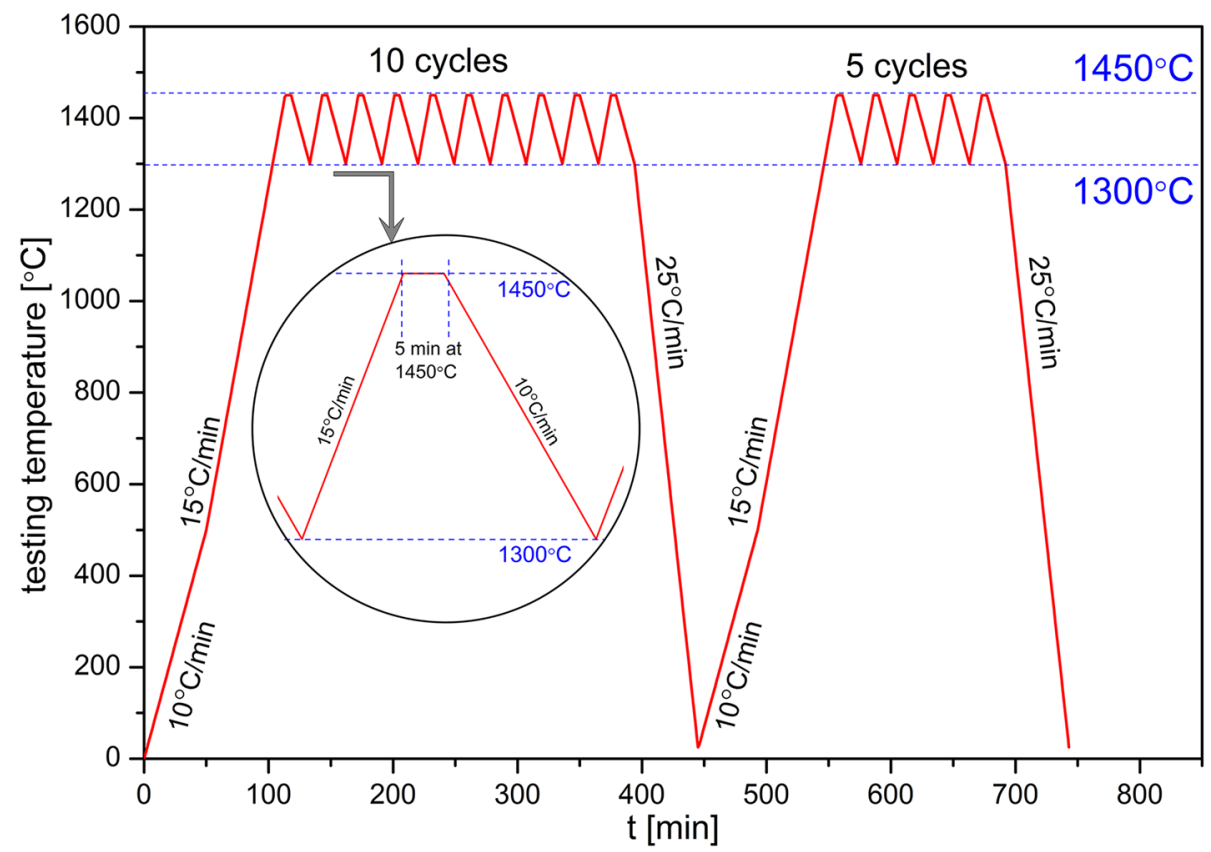

Fig. 1. Temperature profile of the wettability test including 15 heating/cooling cycles of the Si/h-BN couple between $1300^{\circ} \mathrm{C}$ and $1450^{\circ} \mathrm{C}$ with intermediate cooling to room temperature. 
(SEM) coupled with energy dispersive $x$-ray spectroscopy (EDS). The examinations were performed on both top views and cross-sectioned samples.

\section{RESULTS AND DISCUSSION}

\section{Wetting Behavior During Cycling Si Melting/ Solidification Processes}

The fast-forward video recorded during the test is available as the Electronic Supplementary Material 1. What should be noted is that the silicon showed a high cyclic stability in terms of onset and offset temperatures of melting and solidification processes (Fig. 2a). In fact, the melting offset temperatures were close to the theoretical melting point of $\mathrm{Si}$ $\left(T_{\mathrm{m}}=1414^{\circ} \mathrm{C}\right)$, and only a slight decrease was observed during the consecutive cycles. As was also expected, a significant undercooling effect was noted. It was documented that in each cycle the solidification was finished at a temperature around $1345^{\circ} \mathrm{C}$, thus giving $\Delta \mathrm{T} \sim 70^{\circ} \mathrm{C}$. The change of contact angle after melting and holding the Si drop in consecutive cycles is presented in Fig. $2 b$, while a set of corresponding Si drop/h-BN substrate images taken after $5 \mathrm{~min}$ holding at $1450^{\circ} \mathrm{C}$ in each cycle, is presented in Fig. 3. It was found that, during the
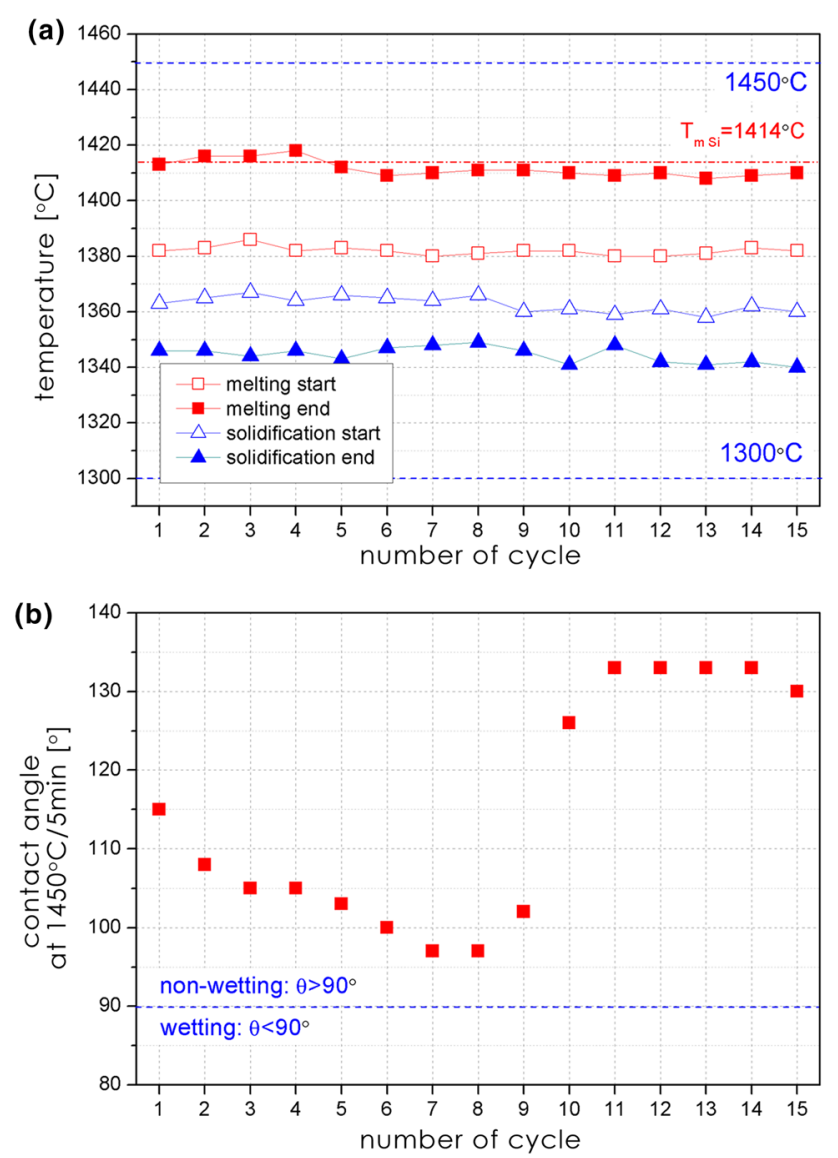

Fig. 2. The recorded temperature ranges of melting and solidification of $\mathrm{Si}$ (a). The average contact angle $\theta_{\mathrm{av}}$ values calculated for Si/h-BN couple during consecutive cycles (b). whole experiment, the contact angle values were within the non-wettability regime (i.e., the $\theta_{\text {av }}$ was higher than $90^{\circ}$ ). However, it was noted that (1) in the 10th cycle, a substantial increase of contact angle from $\theta_{a v} \sim 100^{\circ}$ to $\theta_{\mathrm{av}} \sim 125-130^{\circ}$ took place (Fig. 2b) and (2) the Si drop was spontaneously moved along the substrate surface during subsequent cycles (Fig. 3b).

\section{Structural Characterization of the Si/h-BN Couple After Melting/Solidification Cycles}

A macroscopic view of the $\mathrm{Si} / \mathrm{h}-\mathrm{BN}$ couple after 15 cycles of melting/solidification is shown in Fig. 4a. The presence of some modification of the $h-B N$ surface related to a spontaneous in situ detachment and movement of the Si drop can be distinguished. The results of SEM examinations of this area (Fig. $4 \mathrm{~b}, \mathrm{c}$ ) revealed the presence of fine $\mathrm{h}-\mathrm{BN}$ platelets having different sizes. A difference in the size of the platelets reflects the spontaneous movement path of the Si drop (see Fig. 3b); the smallest were located in the outer zone, while their size increased towards the central part of the h-BN substrate area initially covered by the Si drop. The results of the EDS analysis (Fig. 4d) confirmed the existence of small Si particles (so-called "daughter droplets") that were left behind during movement of the main ("mother") Si drop.

What is important is that there is no evidence for the formation of any interfacial continuous product layers (e.g., silicon nitride $\mathrm{Si}_{3} \mathrm{~N}_{4}$, as was suggested in Ref. ${ }^{8}$. After that, the cross-section of $\mathrm{Si} / \mathrm{h}-\mathrm{BN}$ couple was prepared by using a precise metallographic cutter, while cold-mounting in epoxy resin was first applied to protect the sample (Fig. 5).

The results of SEM inspections carried out on the cross-sectioned sample documented (1) the formation of a platelets zone (with a thickness of $\sim 150$ $\mu \mathrm{m}$ ) in the h-BN substrate's subsurface area (Fig. 6a); (2) a slight change of the chemistry of initially ultra-high-purity $\mathrm{Si}$ towards a Si-B alloy reflected by the presence of a very few $\mathrm{Si}+\mathrm{SiB}_{3}$ eutectic features between the Si grains (Fig. 6b); and (3) a lack of any new products formed at the interface, except for some single needle-like particles observed on the drop side (Fig. 6c). Based on the measured increased content of $\mathrm{B}$ and $\mathrm{N}$, they were recognized as $\mathrm{h}-\mathrm{BN}$ platelets that were detached from the substrate during the thermocycling experiment.

Finally, based on the results of the conducted high-temperature thermocycling test and the structural characterizations of the obtained materials, the following interaction mechanism in the Si/h-BN system during consecutive melting/solidification processes of Si might be proposed. As in the case of our previous experiment, ${ }^{6}$ the interaction is dominated by a slight dissolution of the h-BN substrate in the molten $\mathrm{Si}$, followed by the reprecipitation (a re-growth) of the h-BN platelets during solidification. Consequently, boron from the h-BN 

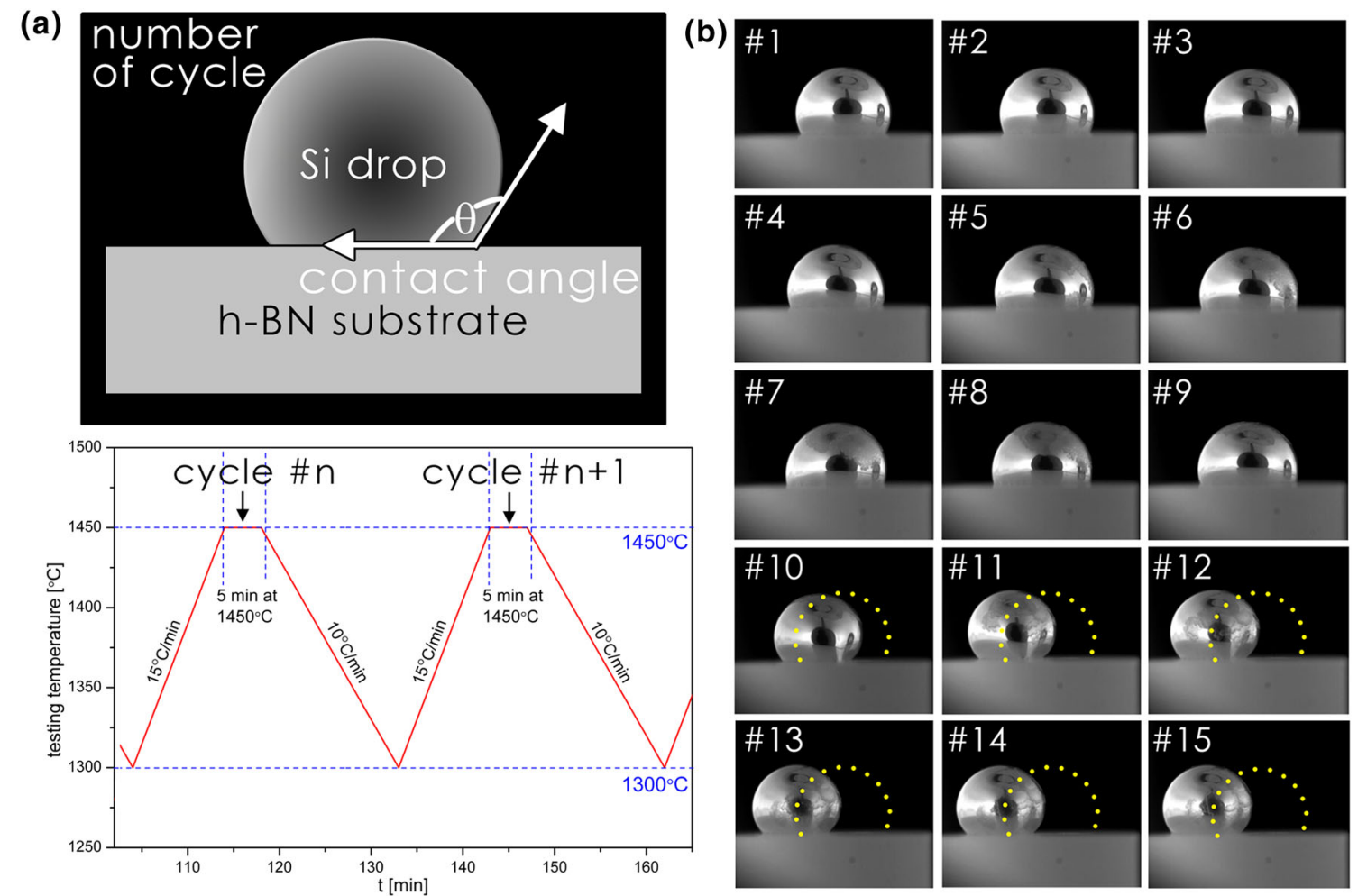

Fig. 3. (a) A schematic showing exemplary Si drop/h-BN substrate image in situ recorded after 5 min holding at $1450^{\circ} \mathrm{C}$ in each cycle. (b) Realtime images captured in each cycle; dotted line on images \#10-15 denotes the position of the drop formed in the first cycle.
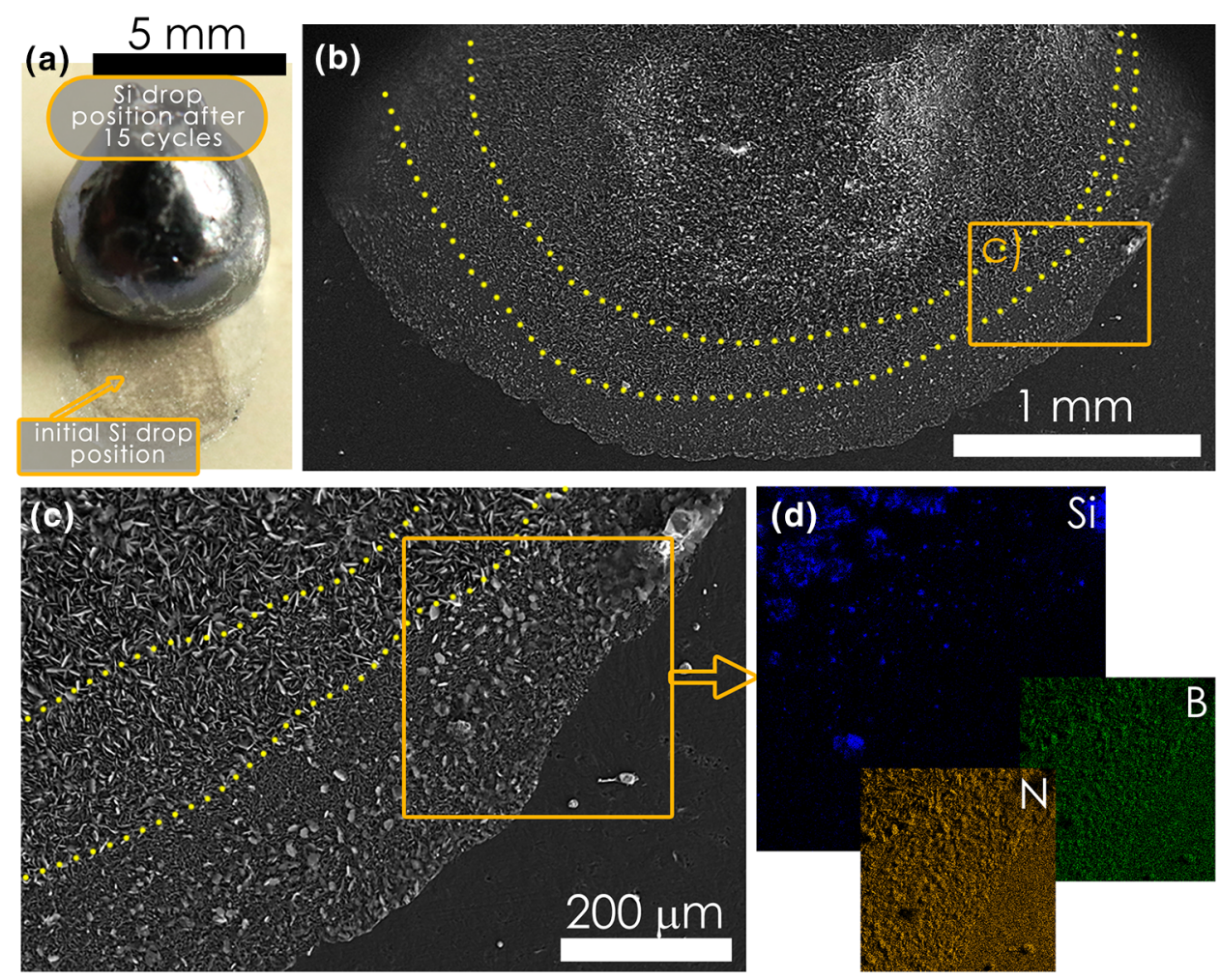

Fig. 4. A macroview of the solidified Si/h-BN couple after 15 melting/solidification steps (a). SEM top-view images showing the part of h-BN substrate that was initially below the Si drop, and then revealed in consecutive cycles (b, c). The EDS mapping confirming an existence of small Si droplets ("daughter droplets") being left after the movement of the main ("mother") drop (d). 
substrate easily diffuses into the molten $\mathrm{Si}$, while nitrogen is released through the gas/liquid interface as a gaseous product due to its very low solubility in Si. By taking into account an extremely high latent heat of boron, ${ }^{2}$ an introduction of small amounts of this element into the PCM candidate should be considered as beneficial in terms of the performance of LHTES devices. Interestingly, in the present work, it has also been documented that the in situ modification of the h-BN surface morphology affects the wetting characteristics in the $\mathrm{Si} / \mathrm{h}-\mathrm{BN}$ system. Most probably, the observed increase of contact angle in the 10th cycle and the movement of Si drop in subsequent cycles is an effect of its uplifting and

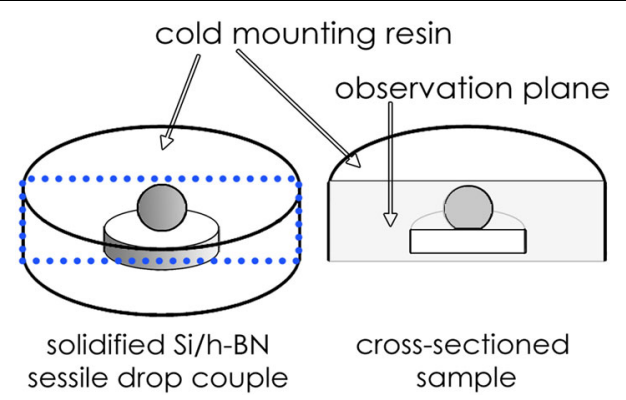

Fig. 5. Sketch of sample preparation for microscopic inspections of cross-sectioned Si/h-BN couple. mechanical pinning on regrown h-BN platelets. Thus, based on the obtained results, the involved interaction mechanism is described as follows:

1. A Si piece is placed on a h-BN substrate having a smooth and flat surface. During the first melting at the temperature of $1414^{\circ} \mathrm{C}$, initially Si does not wet the h-BN substrate. However, when the testing temperature is increased to $1450^{\circ} \mathrm{C}$, the h-BN substrate is slightly dissolved in the molten $\mathrm{Si}$ and the contact angle decreases (Fig. 7a).

2. Upon cooling from $1450^{\circ} \mathrm{C}$ to $1300^{\circ} \mathrm{C}$, the h-BN crystals having a platelet-like morphology reprecipitate in the dissolved substrate area. Since the reprecipitation process takes place at a temperature higher than that needed for the full solidification of the Si drop, a new solid/solid interface is formed in situ. What is important is that a needle-like morphology of grown interfacial h-BN crystals combined with a lack of wettability with molten Si gives a discontinuous contact with the Si drop (Fig. 7b). Furthermore, due to the fact that the contacting substrate surface loses its flatness and smoothness, the recorded contact angles are far from the applicability of Young's equation, and thus they should be treated as apparent in nature. Similar findings on recorded contact angles were noted

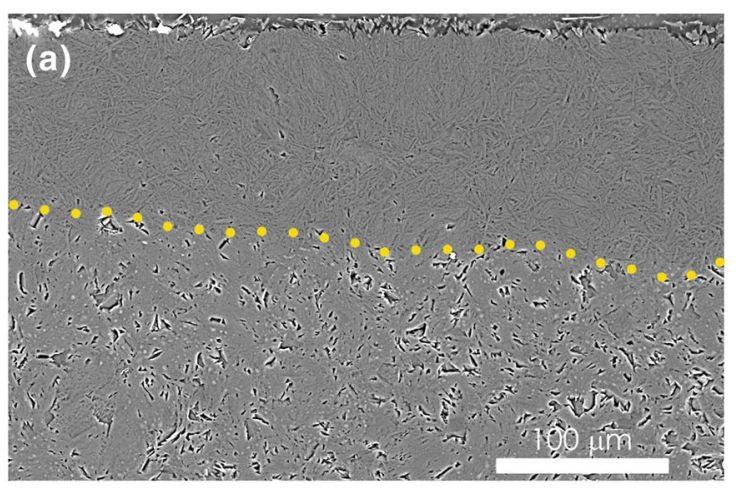

(c)
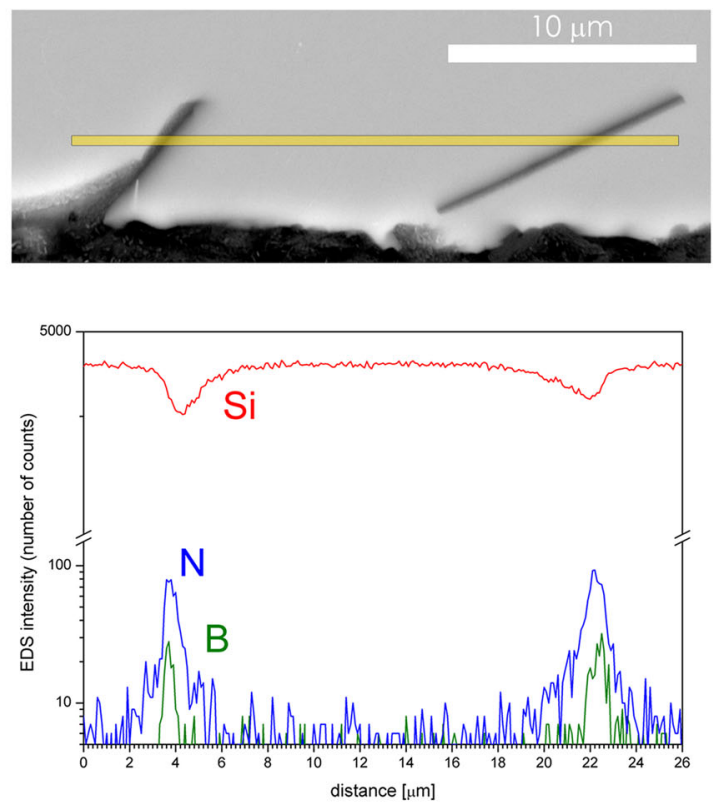

Fig. 6. The results of SEM/EDS examinations of the cross-sectioned Si/h-BN couple after 15 melting/solidification steps showing: (a) formation of platelets zone (with a thickness of $\sim 150 \mu \mathrm{m}$ ) in the h-BN substrate's subsurface area; (b) a slight change of chemistry of initially ultra-highpurity $\mathrm{Si}$ towards a $\mathrm{Si}-\mathrm{B}$ alloy reflected by the presence of a very few $\mathrm{Si}+\mathrm{SiB}_{3}$ eutectic features; (c) the EDS linear analysis confirming the existence of some single detached h-BN platelets on the Si drop side. 

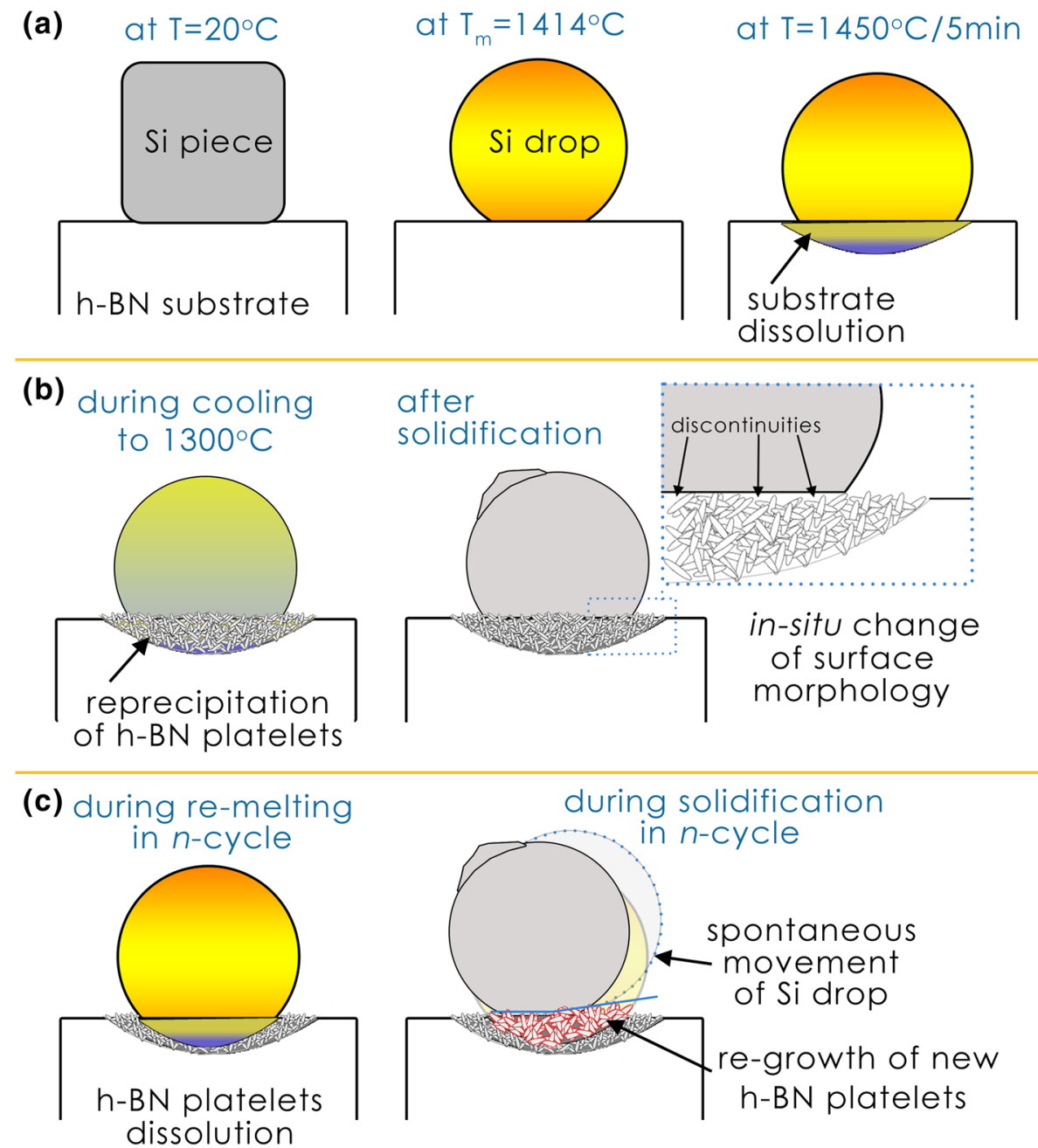

Fig. 7. Schematic drawings of interaction in Si/h-BN system upon cyclic heating/cooling within temperature range of $1300-1450^{\circ} \mathrm{C}$. The drawings show: (a) melting and holding of $\mathrm{Si} / \mathrm{h}-\mathrm{BN}$ at $1450^{\circ} \mathrm{C} / 5 \mathrm{~min}$ in the first cycle; (b) a re-precipitation of h-BN crystals having platelet-like morphology during cooling to $1300^{\circ} \mathrm{C}$; (c) a spontaneous detachment and movement of the Si drop upon multiple melting/solidification processes. More details are shown in the text.

in our recent work, ${ }^{9}$ in which open (and nearsurface) porosity was reactively formed in the hBN-based composite subjected to contact heating with molten Si at an ultra-high temperature.

3. During consecutive melting/solidification cycles the $\mathrm{Si} / \mathrm{h}-\mathrm{BN}$ interface undergoes further changes. The pre-existing h-BN platelets are cyclically dissolved in contact with molten $\mathrm{Si}$, and the new ones are reprecipitated upon cooling to $1300^{\circ} \mathrm{C}$. This behavior results in a prominent differentiation of h-BN platelet size: the largest were observed in areas subjected to the longest direct contact with molten Si. As a consequence of the highly developed inhomogeneous surface topography, the $\mathrm{Si}$ drop can undergo a spontaneous "self-detachment" movement (Fig. 7c).

This behavior is analogous to that described by Liang et al. ${ }^{10}$ showing a superhydrophobicity of highly crystallized h-BN microplatelets formed in accordance with a "surface microarchitecture" approach. They have documented that the presence of such morphological features significantly increases the contact angle value of a water drop on a h-BN substrate, i.e., it gives a so-called "lotus leaf" effect. What is important is that in such a case a lack of perfectly flat and rigid surface conditions makes the recorded contact angle values far from equilibrium, i.e., they are apparent in nature. Although in the present work the wetting characteristic was similar, it should be noted that the orientation of the platelets reprecipitated in consecutive cycles is rather random, so that it is quite hard to exactly predict the behavior of the $\mathrm{Si} / \mathrm{h}-\mathrm{BN}$ system during cycling melting/solidification processes. Nevertheless, in the view of the non-wettability requirement for the selection of refractories for the PCM container, the in situ formation of fine 
h-BN crystals having a platelet-like morphology on the contacting ceramic surface is clearly favorable.

\section{CONCLUSION}

In this work, the performance of a commercial h$\mathrm{BN}$ ceramic in contact with silicon upon its cycling melting/solidification was experimentally examined for the first time. For this purpose, the $\mathrm{Si} / \mathrm{h}-\mathrm{BN}$ couple was subjected to a sessile drop experiment containing 15 cycles of heating/cooling between $1300^{\circ} \mathrm{C}$ and $1450^{\circ} \mathrm{C}$. It was found that $\mathrm{Si}$ on the hBN substrate shows a high cyclic stability in terms of the onset and offset temperatures of melting and solidification processes. It was also documented that the interaction mechanism in the $\mathrm{Si} / \mathrm{h}-\mathrm{BN}$ system is dominated by a slight dissolution of the h-BN in molten Si followed by the reprecipitation of h-BN platelets during cooling. Consequently, although the $\mathrm{Si} / \mathrm{h}-\mathrm{BN}$ systems is characterized by a nonwettability behavior, the regrown platelets randomly alter the surface morphology (and also its smoothness and flatness) in each melting/solidification cycle. As was experimentally documented in this work, such behavior can lead to a prominent change of wetting characteristics of a h-BN refractory being in a contact with molten Si. Additionally, in the view of possible applications of h-BN as PCM container material for Si-based LHTES systems, both in situ slight changes of silicon chemistry towards Si-B alloys as well as the increase of contact angle during consecutive cycles should be considered as beneficial.

\section{ACKNOWLEDGEMENTS}

The project AMADEUS has received funds from the European Union's Horizon2020 research and innovation program, FET-OPEN action, under grant agreement 737054. The sole responsibility for the content of this publication lies with the authors. It does not necessarily reflect the opinion of the European Union. Neither the REA nor the European Commission are responsible for any use that may be made of the information contained therein.

\section{CONFLICT OF INTEREST}

The authors declare that they have no conflict of interest.

\section{OPEN ACCESS}

This article is distributed under the terms of the Creative Commons Attribution 4.0 International License (http://creativecommons.org/licenses/by/4.0/ ), which permits unrestricted use, distribution, and reproduction in any medium, provided you give appropriate credit to the original author(s) and the source, provide a link to the Creative Commons license, and indicate if changes were made.

\section{ELECTRONIC SUPPLEMENTARY MATERIAL}

The online version of this article (https://doi.org/ 10.1007/s11837-019-03364-4) contains supplementary material, which is available to authorized users.

\section{REFERENCES}

1. A. Datas and A. Marti, Sol. Energ. Mat. Sol. C 161, 285 (2017).

2. A. Datas, A. Ramos, A. Martí, C. del Cañizo, and A. Luque, Energy 107, 542 (2016).

3. A. Datas, A.B. Cristobal, C. del Cañizo, E. Antolín, M. Beaughon, N. Nikolopoulos, A. Nikolopoulos, M. Zeneli, N. Sobczak, W. Polkowski, M. Tangstad, J. Safarian, D.M. Trucchi, A. Bellucci, M. Girolami, R. Marx, D. Bestenlehner, S. Lang, A. Vitulano, G. Sabbatella, A. Martí, and A.I.P. Conf, Proc. 2033, 170004 (2018).

4. Z. Yuan, W.I. Huang, and K. Mukai, Appl. Phys. A-Mater. 78,617 (2004).

5. B. Drevet and N. Eustathopoulos, J. Mater. Sci. 47, 8247 (2012).

6. W. Polkowski, N. Sobczak, R. Nowak, A. Kudyba, G. Bruzda, A. Polkowska, M. Homa, P. Turalska, M. Tangstad, J. Safarian, E. Moosavi-Khoonsari, and A. Datas, J. Mater. Eng. Perform. 27, 5040 (2018).

7. N. Sobczak, R. Nowak, W. Radziwill, J. Budzioch, and A. Glenz, Mater. Sci. Eng., A 495, 43 (2008).

8. B. Drevet, R. Voytovych, R. Israel, and N. Eustathopoulos, J. Eur. Ceram. Soc. 29, 2363 (2009).

9. W. Polkowski, N. Sobczak, A. Polkowska, R. Nowak, A. Kudyba, G. Bruzda, D. Giuranno, A. Generossi, B. Pacci, D.M. Trucchi, Metall. Mater. Trans. A:, in press, (2018), h ttps://doi.org/10.1007/s11661-018-5035-z.

10. J. Liang, Y. Huang, J. Lin, C. Feng, C. Yu, X. He, Z. Yan, W. Zhai, and C. Tang, J. Alloy. Compd. 705, 749 (2017).

Publisher's Note Springer Nature remains neutral with regard to jurisdictional claims in published maps and institutional affiliations. 